\title{
Game Comenius: uma proposta digital e lúdica de mídia- educação para licenciandos e professores
}

\begin{abstract}
Dulce Márcia Cruz
${ }^{1}$ Centro de Ciências da Educação - Universidade Federal de Santa Catarina, Campus Reitor João David Ferreira Lima, s/n - Trindade, Florianópolis - SC, 88040-900, Brazil.

dulce.marcia@gmail.com

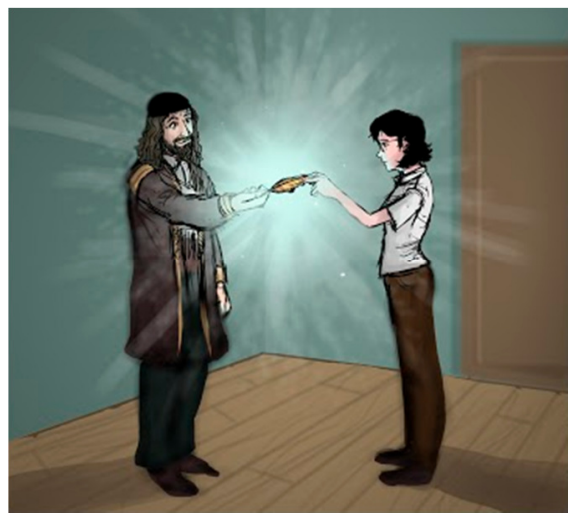

Resumo. O objetivo principal do jogo digital que está sendo produzido para estar disponível gratuitamente online é ensinar professores e alunos de licenciatura a utilizar as mídias na sala de aula como estratégias de ensino e aprendizagem. A justificativa do trabalho decorre da demanda de estudantes e professores letrados digitalmente e adotando um crescente e cada vez mais amplo espectro de mídias que são apropriadas nas práticas sociais, mas ainda pouco utilizadas no planejamento e nas ações pedagógicas. As atividades pedagógicas previstas incluem apresentações expositivas, jogar jogos analiticamente, realizar pesquisas na internet, discussões em grupo, entrevistas, observação participante, entre outras.
\end{abstract}

\section{Cenário de uso}

O jogo virtual Game Comenius pretende ensinar professores e alunos de licenciatura a utilizar as mídias na sala de aula, sendo assim, o software pode ser utilizado tanto com para formação inicial de graduandos de pedagogia e licenciandos como para a formação continuada de professores de qualquer segmento (superior, médio ou fundamental) da educação.

\footnotetext{
${ }^{1}$ Equipe de produção de Mestrado (M) e Iniciação Científica (IC): Ana Cristina Nunes Gomes Müller $^{(\mathrm{M})}$, Fernando Luís Merízio ${ }^{(\mathrm{M})}$, Geovanna dos Passos ${ }^{(\mathrm{M})}$, Isadora Trevisan Locatelli $^{(\mathrm{IC})}$,Renan Pinho Assi ${ }^{(\mathrm{IC})}$, João Victor Queiroz Garcia ${ }^{(\mathrm{IC})}$, Marina Lemos Carcereri Mano $^{(\mathrm{IC})}$,Sandra Luz ${ }^{(\mathrm{M})}$, João Guilherme Eicke ${ }^{(\mathrm{IC})}$. emails: \{aninhagomesmuller, fernandomerizio, geozinhapassos, isadorat.locatelli, renanpinhoassi,garcia.jvq@gmail.com, marinalcmano,_sandraluz.pmf\}@gmail.com, joao_rkn@hotmail.com
} 
V Congresso Brasileiro de Informática na Educação (CBIE 2016)

Anais dos Workshops do V Congresso Brasileiro de Informática na Educação (CBIE 2016)

A justificativa para o projeto é que, no contexto da cultura da convergência, professores e estudantes de licenciatura vêm se apropriando das mídias em suas práticas sociais, mas esse letramento ainda está muito distante da escola. Instituições nacionais e internacionais têm proposto ações e políticas de letramento para incentivar a incorporação das mídias digitais de forma crítica e criativa visando desenvolver as habilidades e competências tanto de estudantes como de professores que poderiam enriquecer os espaços formais de ensino e aprendizagem. Este projeto se insere no movimento das propostas de letramento midiático que tem buscado criar estratégias que incentivem a aprendizagem das linguagens e modos de produção das narrativas e da lógica das mídias digitais traduzidas em práticas didáticas, críticas e criativas no ambiente escolar. A questão norteadora que move este projeto é de que maneira o acesso, a apropriação, o consumo e a produção de mídias nas práticas sociais de sujeitos podem ser ampliados através da participação de professores e estudantes em eventos de letramentos baseados nas linguagens e narrativas digitais. Mais especificamente, este projeto pretende investigar como é possível contribuir para a ampliação dos letramentos digitais através da criação de um jogo digital educativo online cuja temática é a formação para as mídias.

\section{Desenvolvimento}

O objetivo principal desta pesquisa é investigar através da criação do Game Comenius como um jogo digital pode ensinar professores e alunos de licenciatura a utilizar as mídias na sala de aula. A justificativa do trabalho decorre da demanda de estudantes e professores que estão cada vez mais letrados digitalmente e ao crescente número de mídias que são apropriadas nas práticas sociais, mas ainda são pouco utilizadas nas escolas e universidades. $\mathrm{O}$ embasamento teórico buscou autores que trabalhassem com metodologias de ensino, como Masetto (2002) e com o potencial educativo dos videogames como, Gee (2009) McGonigal (2012) e Salen e Zimmerman (2012). A presente proposta integra, desde 2013, o projeto "COMENIUS: uma proposta de pesquisa, produção de jogos eletrônicos e formação docente para as mídias" com apoio da Chamada: Universal 14/2013 (três anos de duração), e, desde 2014, com apoio da Chamada MCTI/CNPQ/MEC/CAPES N ${ }^{\circ}$ 22/2014 Ciências Humanas, Sociais e Sociais Aplicadas (dois anos de duração), intitulado "Comenius: criação de um jogo digital online de formação docente para as mídias" na Universidade Federal de Santa Catarina.

A metodologia está sendo baseada na produção (game design) do jogo e na oferta de oficinas de formação com coleta de dados para melhoria do game e verificação de mudanças no letramento dos participantes.

Em primeiro lugar foi feita uma pesquisa nacional que traçou o perfil midiático dos estudantes de licenciatura, cujos resultados vêm servindo de base para a criação do Game Comenius por uma equipe composta por estudantes de pós-graduação em Educação e graduandos de Psicologia, Design e Computação. Em 2016, as etapas têm sido desenvolvidas em três direções: (1) finalização da primeira versão do jogo; (2) oficinas de testes de melhorias com estudantes e professores visando conseguir novos financiamentos para versões ampliadas do Game Comenius; (3) ofertas de 
V Congresso Brasileiro de Informática na Educação (CBIE 2016)

Anais dos Workshops do V Congresso Brasileiro de Informática na Educação (CBIE 2016)

formação docente através do Game Comenius, com o desenvolvimento de estratégias inovadoras e a avaliação de sua eficácia em diversos contextos formais e informais em projetos de pesquisa de iniciação científica, mestrado, doutorado.

Os métodos de pesquisa utilizados configuram-se como Design Based Research na investigação prática da intervenção educacional. Design Based Research (DEDE, 2004) é um método desenvolvido pela comunidade acadêmica das ciências da aprendizagem, e é por vezes descrito como uma etnografia intervencionista, ou seja, a etnografia de uma atividade projetada. Normalmente trata-se da utilização de diversos métodos (e.g. entrevistas, questionários, observação) como uma forma de compreender uma ecologia de aprendizagem criada pela pesquisa. Normalmente a pesquisa se caracteriza em múltiplas fases de aplicação chamadas iterações; em cada iteração a intervenção ou curso é aprimorado com os conhecimentos gerados na iteração anterior. Design Based Research é coerente com uma perspectiva epistemológica pragmática, e o conhecimento gerado visa informar tanto a teorias como as práticas (na forma de cursos e atividades que podem ser adaptados, replicados, ou informar novas práticas similares).

As atividades pedagógicas previstas incluem apresentações expositivas, jogar jogos analiticamente, realizar pesquisas na internet, discussões em grupo, entrevistas, observação participante, entre outras. Em 2016 será finalizada a primeira versão do jogo digital online visando propor alternativas para a formação com o uso das mídias. Nesta fase de produção tem sido oferecidas oficinas para estudantes de licenciatura da Universidade Federal de Santa Catarina e para professores da educação básica de Florianópolis para testar hipóteses narrativas e de jogabilidade dos games pesquisados possibilitando a coautoria dos jogadores no processo de criação. Eles estão sendo convidados a jogar e, através do exercício de aplicação e reflexão sobre o uso das mídias, a explorar diferentes formas de letramentos dentro de um contexto narrativo que cria a possibilidade de novas aprendizagens. A ação de formação é feita através do Game Comenius que está sendo produzido para dar apoio a uma estratégia de ampliação dos letramentos digitais dos sujeitos investigados. Os resultados mostram que num contexto acadêmico é desafiante criar um jogo educativo lúdico que proponha práticas pedagógicas inovadoras com mídias. As conclusões parciais indicam que os professores e alunos de licenciatura podem ampliar seu letramento midiático a partir das discussões sobre o jogo provocadas pelas oficinas de avaliação do Game Comenius.

Tanto o jogo como os resultados da pesquisa vêm sendo disponibilizados na internet, (Facebook - https://www.facebook.com/gamecomenius/?ref=bookmarks) criado pelo grupo de pesquisa visando ampliar o alcance e continuidade do aperfeiçoamento dessa proposta de formação.

Dentre os instrumentos de avaliação da formação oferecida estão o teste da criação de narrativas digitais multimodais por parte dos jogadores além do estudo das interações no ambiente virtual do jogo. Para a análise dos dados será utilizado um modelo linear geral para verificar a diferença entre os grupos de participantes das diferentes oficinas, controlando as variáveis intervenientes e para compreensão dos 
V Congresso Brasileiro de Informática na Educação (CBIE 2016)

Anais dos Workshops do V Congresso Brasileiro de Informática na Educação (CBIE 2016)

textos produzidos utilizaremos a análise de conteúdo. Assim, espera-se ao mesmo tempo criar conhecimento sobre Game Design no Centro de Educação da UFSC, suprir uma lacuna de jogos educativos voltados para o público adulto contribuindo para a ampliação dos letramentos dos atuais docentes e dos futuros professores para que consigam incorporar as mídias de forma crítica, produtiva e autoral em sua prática pedagógica.

Os softwares utilizados para a criação do jogo estão divididos nas áreas da produção. Na parte pedagógica, programas de editoração e apresentação de textos, como Word, mas novas mídias foram aprendidas e utilizadas durante o projeto, dos quais a criação do grupo Comenius no Whatsapp, para troca de mensagens de forma rápida e imediata, muito útil para consultas e decisões urgentes em tempo integral e just in time; uso do Facebook para servir de divulgação do processo de pesquisa e produção; Skype ou Hangout do Google, para as reuniões de trabalho feitas para driblar as dificuldades circunstanciais de encontro presencial da equipe; aprendizagem de ferramentas como Prezi, Powerpoint e Powtoon pela necessidade da bolsista PIBIC de criar as narrativas que visavam deixar mais claras as ideias ainda não realizadas no protótipo do jogo para a apresentação das oficinas; domínio do Google Drive para criar questionários online para levantar os dados das oficinas; sem contar uma multiplicidade de aplicativos e games que foram e vem sendo continuamente pesquisados e utilizados pelo grupo como material de base para inspirar as decisões.

Na programação, o jogo em fase de construção está sendo desenvolvido em HTML5 e Javascript. Como o objetivo do jogo é alcançar o maior número de mídias e facilitar o acesso dos jogadores, foi decidido construi-lo no Canvas do HTML5 e sua disponibilização seria via site e Facebook. Adotamos o Canvas, pois o HTML5 é nativo de todos os navegadores modernos. Isso significa que o jogador não deverá instalar nenhum plug-in para o acesso. Toda a mecânica do jogo é programada em Javascript, utilizando duas bibliotecas de suporte e programa de criação multimídia: JQuery: Uma poderosa biblioteca que facilita e reduz a quantidade de código escrito. - Flash CC/CreateJS, respectivamente, o programa de criação multimídia que oferece facilidades na questão de animação e desenvolvimento de imagens vetoriais e a biblioteca adotada pela ferramenta. Para o jogo, todo o conteúdo foi criado na nova funcionalidade do Flash CC, exportação para Canvas/HTML.

Os programas utilizados pelos bolsistas da Arte são principalmente o Adobe Photoshop CC2015 para cenários e o Adobe Flash 2015 para as animações.

\section{Apresentação do Software}

O jogo já está disponível para teste no endereço aberto e gratuito: http://gamecomenius.com/prototype/

Um teaser do jogo foi feito em 2015 e resume a proposta daquele momento, que foi alterada, mas que mostra de certa maneira o que vem sendo feito. $\mathrm{O}$ vídeo pode ser visto no link https://www.youtube.com/watch?v=2y0aWRntYBM 
No endereço do jogo não é necessário cadastro. O jogador pode primeiro passar pelo tutorial que ensina as principais ações iniciais. Depois, ao entrar no jogo, uma história em quadrinhos digital (HQ) explica em poucas imagens qual é o plot do jogo, ou seja, qual é o problema que nossa heroína, a professora Lurdinha, terá que resolver em seu caminho pelo século XXI. A partir da primeira vez é possível continuar o jogo, já que o sistema utilizado guarda o que foi feito naquele endereço.

A HQ mostra a professora Lurdinha, estudando em seu quarto no ano de 1965 quando Comenius, o pai da Didática, aparece para ela. Afirma que foi ao futuro e as máquinas dominam a educação e os alunos não gostam mais de ir para a escola e os professores não conseguem mais acompanhar as mudanças que o mundo está passando. E coloca a missão para a jovem professorinha: vá até o futuro, aprenda a dominar as mídias e utilizá-las em suas estratégias didáticas e volte para ensinar o que fazer. Para isso, Lurdinha irá passar por uma aprendizagem/letramento midiático, tentando entender como o planejamento didático pode incluir a multimodalidade, as diferentes linguagens e que a escola não é apenas o lugar da escrita mas de todas as culturas que as mídias podem colaborar para uma educação mais cidadã, inclusiva, crítica, produtiva e criativa.

A mecânica do jogo se baseia em escolhas que serão pontuadas através do alcance do objetivo das missões que envolvem saber qual habilidade precisa desenvolver nos alunos, o contexto e a descrição de como fazer. As escolhas são divididas em como fazer (procedimentos ou tipos de aula), estratégias (modo de agrupar as atividades dos alunos), espaços de aprendizagem (sala de aula, biblioteca, sala multimeios e laboratório de informática) e mídias (distribuídas em quatro gerações: impresso, audiovisual, hipermídia e realidade aumentada).

As escolhas levam à sala de aula, onde a professora também terá que decidir como realizar seu planejamento no início, meio e fim da aula, tendo que lidar com os problemas que ocorrem no dia a dia (falta de luz ou internet, tomadas que não encaixam etc.).

Ao terminar a aula a professora pode passear pela praça da cidade para aumentar seus letramentos indo ao cinema, ao museu, à biblioteca, ou passeando livremente. Nesses espaços, minigames lhe ajudarão a aumentar sua pontuação e conhecimento cultural, dentre outros achievements. O jogo recomeça no quarto, quando a professora volta para descansar e recuperar energias para mais um dia de escolhas, erros e acertos.

O protótipo já permite uma jogada completa, mas ainda não totalmente implementada, tendo ainda bastante trabalho pela frente, muitas ações em fase de produção e ainda não disponíveis, apesar de já decididas.

O que está já aberto ao público são as seguintes telas jogáveis:

Tela inicial: na qual são abertos os botões jogar, novo jogo e tutorial. Jogar: Botão para continuar um jogo salvo. Novo Jogo: Botão para iniciar uma nova partida. Tutorial: Mostra o tutorial do jogo, que explica como jogar a primeira missão. 
V Congresso Brasileiro de Informática na Educação (CBIE 2016)

Anais dos Workshops do V Congresso Brasileiro de Informática na Educação (CBIE 2016)

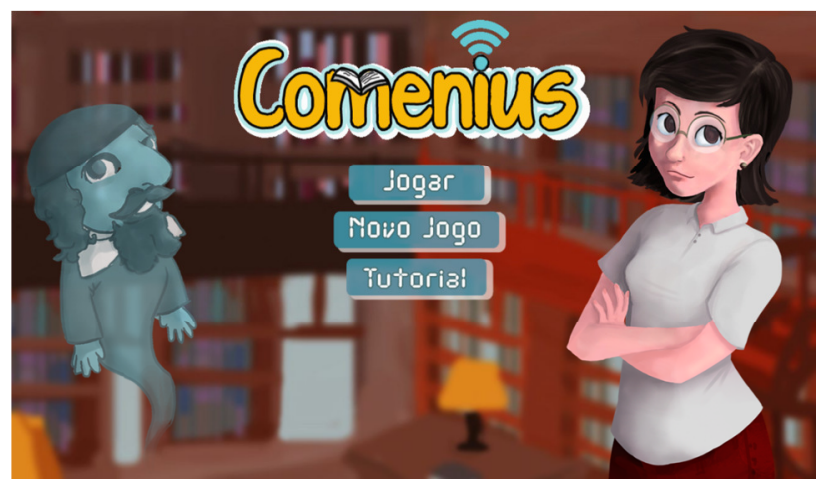

Quarto da Lurdinha: Ao entrar no jogo, no cenário inicial há uma agenda. Nela, no canto esquerdo, estão as informações da fase atual.

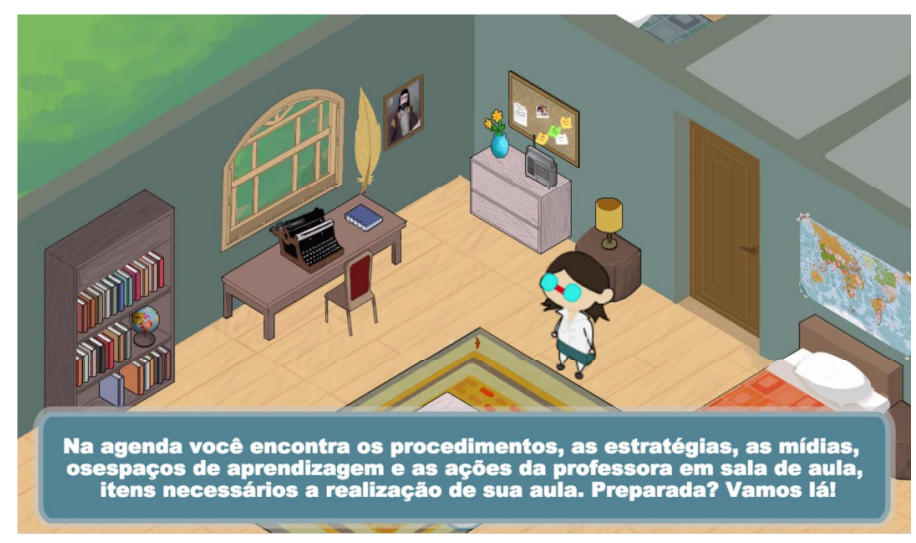

Agenda: No canto direito, é onde o jogador deverá esquematizar a sua aula. O jogador recebe uma missão (o objetivo da aula) e precisa escolher onde, como e com que mídias irá realizar essa aula. Após as escolhas, o jogo vai para a tela de ação para a aula.

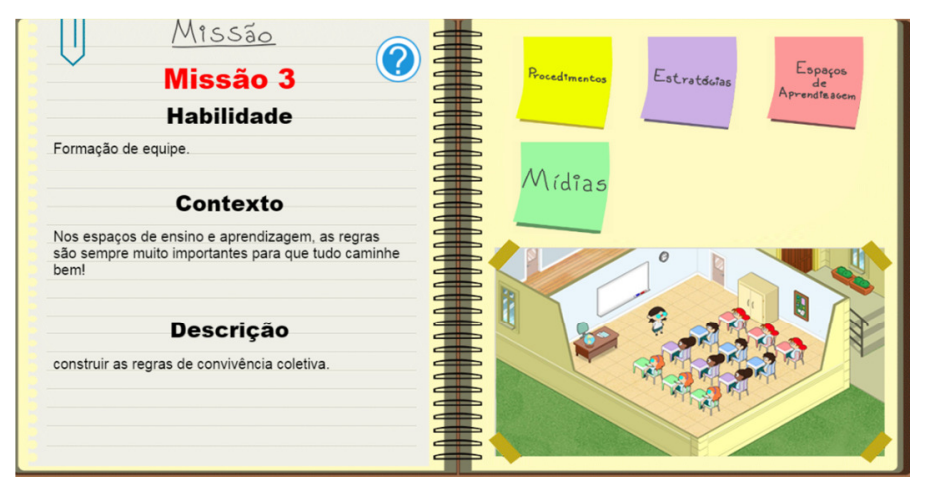

Tela para ações da aula: o jogador precisa escolher duas estratégias que irá usar durante a aula. A partir dessas escolhas, o jogador aplica suas escolhas na sala de aula. 
V Congresso Brasileiro de Informática na Educação (CBIE 2016)

Anais dos Workshops do V Congresso Brasileiro de Informática na Educação (CBIE 2016)

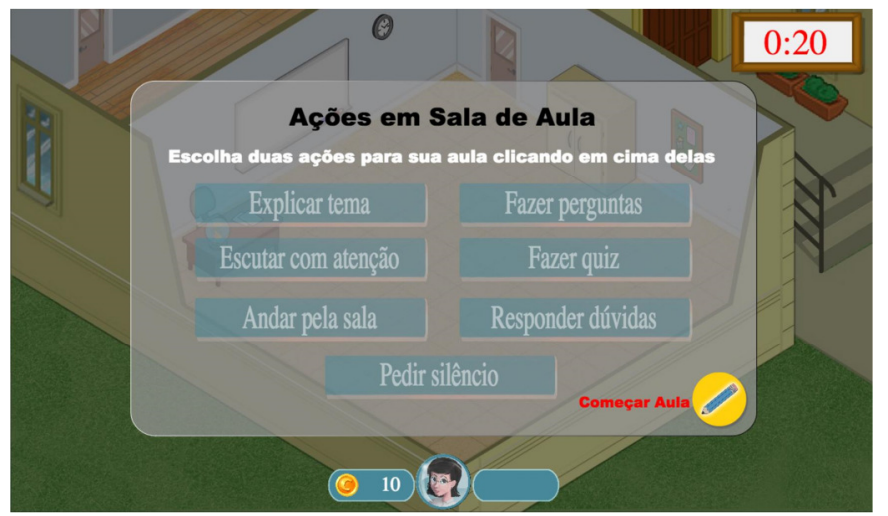

Sala de aula: onde ocorrem as aulas e que irão simular as possibilidades de erro e acerto com as condições existentes nas salas das escolas.

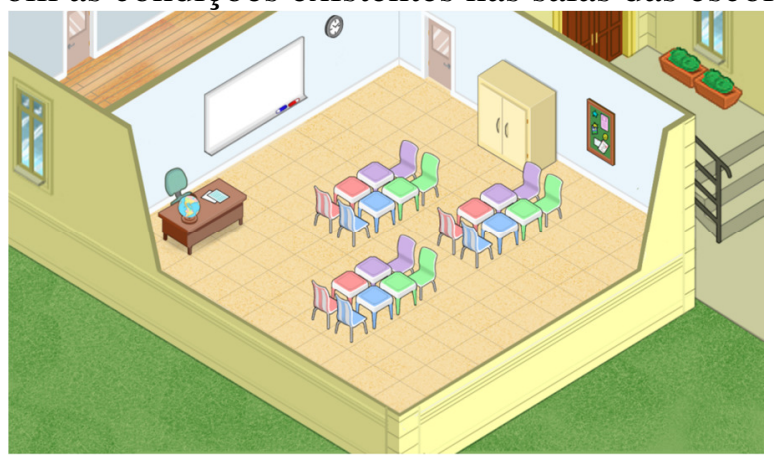

Praça: Aqui o jogador poderá entrar no cinema, no museu e na biblioteca para aumentar seu conhecimento, respondendo a quizzes de diferentes gêneros, ou voltar a sua casa, para ir para a próxima fase.

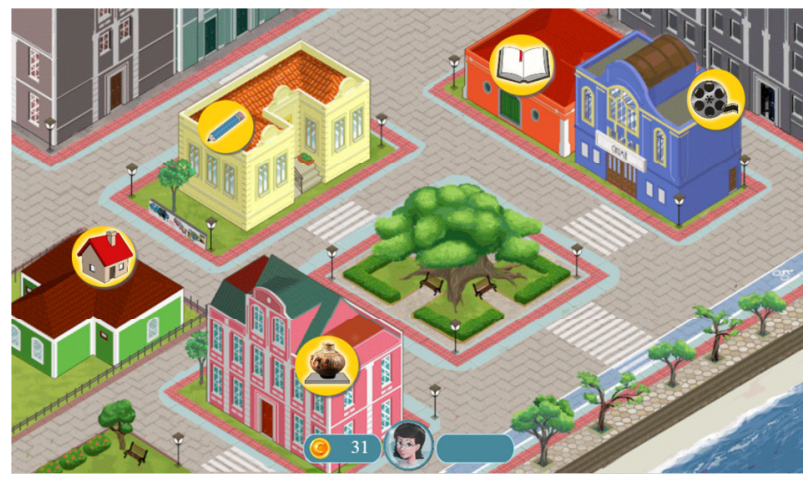

\section{Considerações finais}

O Game Comenius busca contribuir para o letramento de professores e alunos de licenciatura, juntando teorias de metodologia de ensino e game designer, o jogo procura através da educação e diversão fazer com que seus jogadores reflitam sobre as escolhas e os procedimentos que devem ser tomados antes e durante suas aulas, propiciando assim um espaço de melhor aprendizado para seus alunos. Estando em seu terceiro protótipo, Game Comenius já passou por três oficinas com alunos de pedagogia da Universidade Federal de Santa Catarina e por uma oficina na $14^{\mathrm{a}}$ 
V Congresso Brasileiro de Informática na Educação (CBIE 2016)

Anais dos Workshops do V Congresso Brasileiro de Informática na Educação (CBIE 2016)

Semana de Ensino, Pesquisa e Extensão (SEPEX) da UFSC. Nessas oficinas foram oferecidos formulários para que os participantes dessem seu feedback sobre o jogo, formulários para uma pesquisa do perfil midiático dos participantes, apresentações sobre a equipe Game Comenius e como este vem sendo desenvolvido e uma roda de conversa no final para depoimentos e comentários a respeito do que foi aprendido. Através dos formulários de feedback e dos comentários ao final de cada oficina, que são as iterações do método utilizado, a equipe de desenvolvedores do jogo vem discutindo, alterando e melhorando o jogo seguindo as exigências do público.

A complexidade de simular as escolhas que devem ser feitas para ensinar tem sido um grande desafio para a equipe, formada por estudantes, tempo parcial de dedicação e com pouca experiência de game design e escassa verba para a produção. Mas em suas primeiras oficinas já podemos perceber que o objetivo de ampliar os letramentos dos participantes já se faz notar pelas avaliações feitas. $\mathrm{O}$ fato de refletir sobre o game, responder sobre mecânica, estética, narrativa etc. do jogo e propor melhorias a partir de suas experiências pode ser considerado um modo lúdico de aprender a pensar as mídias na sala de aula, não apenas dentro do jogo, mas pela reflexão sobre a prática. Esperamos conseguir mais financiamento para manter a equipe e a produção, bem como, ao finalizar a primeira versão, seguir utilizando o game em oficinas de formação continuada. Ao mesmo tempo, o fato de estar disponível online pode levar a proposta a lugares e jogadores os mais diversos. Para todos/as esperamos que aprender a ensinar também seja uma experiência lúdica, prazerosa e motivadora.

\section{Agradecimentos}

Agradecemos ao $\mathrm{CNPq}$ pelas bolsas de apoio técnico e de mestrado bem como verba para financiamento do projeto.

\section{Referências}

DEDE, C. (2004) If Design-Based Research is the Answer, What is the Question? A Commentary on Collins, Joseph, and Bielaczyc; di Sessa and Cobb; and Fishman, Marx, Blumenthal, Krajcik, and Soloway in the JLS Special Issue on DesignBased Research. Journal of the Learning Sciences, v. 13, n. 1, p. 105-114.

GEE, James Paul. (2009). "Bons video games e boa aprendizagem". Perspectiva 27.1, p. 167-178.

MASETTO, Marcos T. (2002) Competência Pedagógica do professor universitário. São Paulo: Summus, p. 73-139.

MCGONIGAL, Jane. (2012) "A realidade em jogo: por que os games nos tornam melhores e como eles podem mudar o mundo." Rio de Janeiro: BestSeller, 2012.

SALEN, Katie; ZIMMERMAN, Eric. (2012) Regras do jogo: fundamentos do design de jogos. São Paulo: Edgard Blucher, v.3. 